\title{
Angiotensin-(1-7) Alleviates Autophagy Response Through the PI3K/Akt/mTOR Signaling Pathway in Severe Acute Pancreatitis
}

\section{Chunyun Li}

Beijing Obstetrics and Gynecology Hospital

\section{Xiaozheng $\mathrm{Yu}$}

Beijing Obstetrics and Gynecology Hospital

\section{Yinan Guo}

Beijing Obstetrics and Gynecology Hospital

\section{Xueyan Wang}

Beijing Obstetrics and Gynecology Hospital

Ruixia Liu ( $\sim$ liuruixia@ccmu.edu.cn )

Beijing Obstetrics and Gynecology Hospital

Chenghong Yin

Beijing Obstetrics and Gynecology Hospital

\section{Research Article}

Keywords: autophagy, angiotensin-(1-7), severe acute pancreatitis, LC3, p62/SQSTM, BEZ235

Posted Date: January 18th, 2021

DOI: https://doi.org/10.21203/rs.3.rs-130905/v1

License: (c) (i) This work is licensed under a Creative Commons Attribution 4.0 International License. Read Full License 


\section{Abstract}

Background. Severe acute pancreatitis (SAP) is a fatal medical emergency. The autophagy response is essential for cellular homeostasis, and plays an important role in SAP. We aimed to determine if angiotensin-(1-7), abbreviated as Ang1-7, regulates the autophagy response in SAP and to elucidate the underlying mechanism.

Methods. We used a rat model to investigate the effects of Ang1-7 on pancreatic pathomorphological damage and the autophagy response, which were evaluated using histological scoring and the quantification of the autophagy markers microtubule-associated protein 1 light chain 3 (LC3) and p62/SQSTM (p62) by western blotting and immunohistochemistry. We treated rat pancreatic acinar AR42J cells with caerulein (CAE) to build an in vitro model. To prevent degradation of the autophagy markers, so that we could determine the increase in autophagic vacuolization, we used chloroquine to inhibit autophagosome and lysosome fusion. The PI3K inhibitor BEZ235 was used to suppress $\mathrm{PI} 3 \mathrm{~K} / \mathrm{Akt} / \mathrm{mTOR}$ signaling. We observed the impact of Ang1-7 on the autophagy response and evaluated the underlying mechanism by detecting protein expressions of LC3 and p62.

Results. In the rat SAP model, Ang1-7 significantly relieved pancreatic pathological damage. Ang1-7 also reduced autophagy protein markers, including the LC3- $₫$ to LC3- $\$ ratio and the p62 level. In AR42J cells, the autophagy markers significantly increased after treatment with CAE and chloroquine. The autophagy response was significantly alleviated after treatment of the cells with Ang1-7, while blocking the $\mathrm{PI} 3 \mathrm{~K} / \mathrm{Akt} / \mathrm{mTOR}$ pathway remarkably counteracted this effect.

Conclusions: Our results indicated that Ang1-7 alleviated the autophagy response in SAP via the $\mathrm{PI} 3 \mathrm{~K} / \mathrm{Akt} / \mathrm{mTOR}$ signaling pathway.

\section{Background}

Acute pancreatitis (AP) is a leading cause of inpatient care among gastrointestinal conditions ${ }^{[1]}$. The annual incidence rate of AP ranges from 5 to 30 cases per 100,000 people ${ }^{[2]}$. Approximately $20 \%$ of all AP cases progress to severe acute pancreatitis (SAP), which carries a mortality rate of $8-39 \%$, and exacts a heavy toll on both families and the society at large ${ }^{[3-5]}$.

It is generally believed that abnormal intra-acinar activation of trypsinogen and the concomitant inflammatory reaction are key events in the early stage of SAP ${ }^{[6-8]}$. Autophagy has been reported to play an important role in both premature trypsin activation and inflammation ${ }^{[9-15]}$. Autophagy is essential for cellular homeostasis in eukaryotic cells to degrade obsolete intracellular organelles and long-lived proteins during normal differentiation as well as pathological changes ${ }^{[16,17]}$. Studies have found that autophagy often fails to maintain cellular functions in multiple diseases, including cardiovascular, infectious, neoplastic, and metabolic diseases as well as inflammatory bowel disease ${ }^{[18,19]}$. Autophagy can act as both a protector and a killer of cells, depending on the stage of the disease and the 
surrounding cell environment ${ }^{[20]}$. Given its broad clinical implications, autophagy has become a major target for drug discovery and development ${ }^{[21]}$. Hashimoto et al. (2008) ${ }^{[9]}$ first found that the knockout of autophagy-related gene 5 (ATG5), which is required for autophagosome formation, greatly ameliorated AP and decreased trypsin activation in mice. Since then, several other studies have also reported that autophagy plays an important role in AP by regulating the activation of intra-acinar digestive enzymes during the early stage of pancreatitis ${ }^{[10-12]}$. Furthermore, changes in the autophagy response in pancreatitis influence the inflammatory response ${ }^{[13-15]}$.

Angiotensin-(1-7), hereafter abbreviated as Ang1-7, is a small-molecule bioactive peptide belonging to the renin-angiotensin system that serves as an endogenous antagonist of angiotensin II. Human plasma concentrations of Ang1-7 range from 1.0 to $9.5 \mathrm{pmol} / \mathrm{L}^{[22]}$. In 2012, our team first found that high levels of Ang1-7 were expressed in the pancreas of a mouse SAP model, and that the basal level of Ang1-7 in the pancreatic tissue and serum of the SAP mice was between 3 and $15 \mu \mathrm{g} / \mathrm{mL}$ [23]. We also found that Ang1-7 could exert a protective role in restoring pancreatic microcirculation as well as reducing pancreatic injury and inflammatory responses ${ }^{[24-26]}$. However, the other effects of Ang1-7 on the pancreatic response in AP remain unclear.

In this study, we aimed (i) to determine whether Ang1-7 could alleviate the autophagy response in pancreatic acinar cells during SAP in both in vivo and in vitro models and (ii) to discover the underlying mechanisms.

\section{Materials And Methods \\ 2.1 Materials}

The various chemicals, antibodies, and other materials used in this experiment, along with their manufacturers, are listed below: angiotensin fragment 1-7, sodium pentobarbital, chloroquine diphosphate salt (C6628), and caerulein (CAE) were purchased from Sigma-Aldrich (Merck KGaA, Darmstadt, Germany); sodium taurocholate from Solarbio (Beijing, China); Rat Amylase (ab102523) and Lipase (ab102524) Activity Assay Kits, rabbit anti-rat microtubule-associated protein 1 light chain 3 A/B (LC3区/囚) multiclonal antibody (ab62721), and rabbit anti-rat p62/SQSTM (p62) multiclonal antibody (ab91526) from Abcam (Cambridge, United Kingdom); rabbit anti-rat Akt (pan) antibody (\#4691), rabbit anti-rat phospho-Akt (Ser473) antibody (\#4060), rabbit anti-rat mTOR antibody (\#2983), and rabbit anti-rat phospho-mTOR (Ser2448) antibody (\#5536) from Cell Signaling Technology Inc. (Danvers, MA, USA); dactolisib (BEZ235, NVP-BEZ235) from Selleck Chemicals (Houston, TX, USA); mouse $\beta$-actin monoclonal antibody (TA-09), goat anti-rabbit and goat anti-mouse secondary antibodies, and biotinylated goat anti-rabbit IgG antibody from ZSJQ-BIO (Beijing, China); F-12K medium from American Type Culture Collection (ATCC; Manassas, VA, USA); fetal bovine serum from Gibco (Thermo Fisher Scientific Inc., Waltham, MA, USA); protease inhibitor, protein phosphatase inhibitor, phenylmethylsulfonyl fluoride (PMSF), and radioimmunoprecipitation assay (RIPA) lysis buffer from 
Applygen (Beijing, China); BCA Protein Assay Kit from Bioss (Beijing, China); polyvinylidene fluoride (PVDF) membranes $(0.45 \mu \mathrm{m}$ and $0.22 \mu \mathrm{m})$ and enhanced chemiluminescence $(E C L)$ kits from Millipore (Darmstadt, Germany); and the Image Lab software from Bio-Rad (Hercules, CA, USA).

\subsection{Animal models and grouping}

Specific pathogen-free male Wistar rats (age, 8-10 weeks; weight, 200-250 g) were purchased from Charles River (Beijing, China). The animals were housed in a standard climate-controlled breeding room, with stable surroundings, an indoor temperature of $22^{\circ} \mathrm{C} \pm 1{ }^{\circ} \mathrm{C}$, and 12 -h light-dark cycles, and fed on standard laboratory chow with water ad libitum. The rats acclimatized for 1 week before being randomly assigned to different groups.

Rats were randomly divided into the following groups: sham operation group (control), SAP groups $(2,12$, 24 , and $48 \mathrm{~h}$, these time points refer to the time elapsed after the injection of sodium taurocholate), and Ang1-7 group. Each group included 8 rats. After a week of acclimatization, the rats were anesthetized using an intraperitoneal injection of sodium pentobarbital ( $50 \mathrm{mg} / \mathrm{kg}$ body weight). The biliopancreatic duct was occluded at the distal duodenum using a vascular clip. In the SAP groups, the canal was infused slowly with freshly prepared $3.75 \%$ sodium taurocholate $(0.1 \mathrm{~mL} / 100 \mathrm{~g}$ body weight) through a 1$\mathrm{mL}$ syringe. Rats of the Ang1-7 group were immediately administered Ang1-7 (25 $\mu \mathrm{g} / \mathrm{kg}$ weight), which was injected into a caudal vein, after the induction of SAP. The control group received an injection of the corresponding volume of normal saline. The time of death of the rats in each group was recorded for the calculation of mortality rate. After the rats were sacrificed, blood and pancreatic tissues were collected for the following experiments.

\subsection{Cell culture and treatment}

Rat pancreatic acinar AR42J cells from ATCC were cultured in F-12K medium supplemented with $20 \%$ fetal bovine serum, $100 \mathrm{U} / \mathrm{mL}$ penicillin, and $100 \mu \mathrm{g} / \mathrm{mL}$ streptomycin (complete medium) at $37^{\circ} \mathrm{C}$ in a humidified atmosphere containing $5 \% \mathrm{CO}_{2}$. The cells were stimulated with $10^{-6} \mathrm{~mol} / \mathrm{L} \mathrm{CAE}$ to induce AP in vitro. Chloroquine $(10,20$, or $40 \mu \mathrm{mol} / \mathrm{L})$ was used to impede the fusion of autophagosomes and lysosomes. Some cells were pretreated with different concentrations of Ang1-7 (0.1, 1, or $10 \mu \mathrm{mol} / \mathrm{L})$ and/or BEZ235 $(100 \mu \mathrm{mol} / \mathrm{L})$. A vehicle containing 2.5\% fetal bovine serum was used to starve the cells for $12 \mathrm{~h}$ before stimulation with drugs. At $24 \mathrm{~h}$ after drug administration, the cells were harvested for the subsequent experiments. The control-group cells were collected without any special treatment.

\subsection{Enzyme-linked immunosorbent assay}

Blood samples, after standing for $2 \mathrm{~h}$, were centrifuged at $3000 \mathrm{rpm}$ for $5 \mathrm{~min}$ to separate the serum. The serum a-amylase (AMYa) level was measured using the Amylase Assay Kit, and lipase activity was measured using the Lipase Activity Assay Kit, according to the manufacturer's instructions.

\subsection{Histopathological analysis}


Transverse sections $(4 \mu \mathrm{m})$ were incised from paraffin-embedded pancreatic tissues, and then, stained with hematoxylin-eosin for histopathological assessment. Histological scoring of the pancreas was performed using a blinded method, as described by Schmidt et al. ${ }^{[27]}$. Morphometric documentation, including evaluation of bleeding, inflammation, necrosis, and edema, was obtained by mapping the surface of the pancreas into 10 geographic fields and evaluating each field independently. The histological scores ( 0 to 4 for each item, representing varying levels of severity) were used to evaluate the pathological severity of AP in each rat.

\subsection{Immunohistochemistry}

In brief, the paraffin-embedded sections were de-paraffinized, rehydrated using an ethanol gradient, blocked to avoid nonspecific antibody binding, and then incubated overnight with anti-LC3A/B (1:50) and anti-p62 (1:50) antibodies at $4{ }^{\circ} \mathrm{C}$. The following day, the sections were incubated with biotinylated goat anti-rabbit IgG antibody, followed by incubation with an avidin-biotin peroxidase complex. Localization of the peroxidase conjugates was achieved using the substrate diaminobenzidine tetrahydrochloride. The sections were counterstained with Mayer's hematoxylin.

\subsection{Western blotting analysis}

Pancreatic tissue samples were lysed with a lysis buffer consisting of protease inhibitor, protein phosphatase inhibitor, PMSF, and RIPA lysis buffer. The total protein concentration was determined with a BCA Protein Assay kit. Then, the proteins were separated using sodium dodecyl sulfate-polyacrylamide gel electrophoresis and transferred onto PVDF membranes. The membranes were first incubated with $5 \%$ non-fat dry milk for $2 \mathrm{~h}$ at room temperature on a shaking-table, and then incubated overnight with the primary antibodies $(1: 1000)$ at $4^{\circ} \mathrm{C}$. All the antibodies were diluted in Tris-buffer saline/Tween 20 (TBST). After being washed three times with TBST, the membranes were incubated for $1-2 \mathrm{~h}$ with peroxidaseconjugated goat anti-rabbit or goat anti-mouse secondary antibodies (1:5000 diluted in TBST). After another three washes with TBST, ECL was used to detect immune reactive bands, and densitometric analysis of the bands was performed using Image Lab software.

\subsection{Statistical analysis}

All data were expressed as mean \pm standard deviation (SD). Statistical analysis was carried out using SPSS software (ver. 21.0; SPSS Inc., Chicago, IL, USA). One-way analysis of variance with either the Kruskal-Wallis or Friedman test was used for multiple comparisons among different groups. Differences were considered statistically significant at $P<0.05$. Kaplan-Meier survival curves were generated for survival analyses using the log rank or Gehan-Breslow-Wilcoxon test.

\section{Results}

\subsection{Autophagy markers were upregulated in the rat SAP model}


Kaplan-Meier survival curves were generated for survival analyses (Fig. 1A). The results showed that the peak of the death toll in the SAP rats occurred between $12 \mathrm{~h}$ and $24 \mathrm{~h}$ after the injection of sodium taurocholate, and the mortality rate was $20.7 \%$ within $48 \mathrm{~h}$.

The AMYa level and lipase activity showed a significant rising tendency, peaking at $12 \mathrm{~h}$ and $2 \mathrm{~h}$ respectively, and then declining over time (Fig. 1B and 1C). Optical microscopic images of the rat SAP models from different groups showed the pathological changes in the pancreatic tissue (Fig. 1D). The pathological scores for bleeding, inflammation, necrosis, and edema ( 0 to 4$)$ obvious increased over time. The bleeding and edema scores peaked at $24 \mathrm{~h}$, and the inflammation and necrosis scores peaked at $48 \mathrm{~h}$ (Fig. 1E) $(\mathrm{P}<0.05)$.

The ratio of LC3- $₫$ to LC3- $\$ and the protein level of p62 significantly increased $(P<0.05) 24 \mathrm{~h}$ after the induction of SAP, peaking at $24 \mathrm{~h}$ (Fig. $1 \mathrm{~F}$ and $1 \mathrm{G}$ ). Therefore, the 24-h SAP group was selected for the subsequent in vivo experiments.

\subsection{Ang1-7 alleviated pancreatic damage in rats with SAP}

As shown in Fig. 2, Ang1-7 could attenuate pathological injury in rats with SAP. Alleviation of interstitial bleeding, inflammatory cell infiltration, pancreatic acinar cell necrosis, and edema could be seen in the Ang1-7 group as compared with the SAP group $(P<0.05)$. Moreover, the pathological scores were significantly reduced by Ang1-7 administration $(P<0.05)$.

\subsection{Ang1-7 decreased elevated autophagy-related proteins in rats with SAP}

Immunohistochemical analysis of autophagy-related proteins in the pancreas showed that LC3 and p62 were expressed within the cytoplasm of pancreatic acinar cells (Fig. 3A). The results of the western blotting analysis are shown in Fig. 3B, 3C, and 3D. Compared with the SAP group, the Ang1-7 group showed remarkable decreases in the ratio of LC3- $\$ to LC3- $\$ and the protein level of p62 $(P<0.05)$.

\subsection{Chloroquine blocked autophagosome degradation in AR42J cells}

We treated AR42J cells with $10^{-6} \mathrm{~mol} / \mathrm{L}$ CAE to establish an in vitro AP model. Different concentrations of chloroquine (10,20, and $40 \mu \mathrm{mol} / \mathrm{L})$ were used to inhibit the fusion of autophagosomes and lysosomes. We observed that the degree of aggregation of the LC3 and p62 proteins depended on the drug concentration (Fig. 4). We used the concentration of $40 \mu \mathrm{mol} / \mathrm{L}$ chloroquine in the subsequent experiments to observe the changes in the autophagy response.

\subsection{Ang1-7 alleviated the autophagy response in an in vitro model of CAE-induced pancreatitis}

AR42J cells were stimulated with different concentrations of Ang1-7 (0.1, 1, and $10 \mu \mathrm{mol} / \mathrm{L})$, along with CAE and chloroquine. We found that both the ratio of LC3-II to LC3-I $(P>0.5)$ and the p62 level $(P<0.05)$ 
were reduced in a drug concentration-dependent manner (Fig. 5A and 5B), although the former had no statistical significance. We used the concentration of $10 \mu \mathrm{mol} / \mathrm{L}$ Ang1-7 in the subsequent experiments as the Ang1-7 group.

\subsection{Autophagy response rebounded after blocking the PI3K/Akt/mTOR pathway}

AR42J cells in the BEZ235 group were treated with $100 \mu \mathrm{mol} / \mathrm{L} \mathrm{BEZ235,} \mathrm{to} \mathrm{impede} \mathrm{the} \mathrm{PI3K/Akt/mTOR}$ signaling pathway, along with $\mathrm{CAE}$, chloroquine, and Ang1-7 (Fig. 6A and 6B). Compared with the Ang1-7 group, the BEZ235 group showed a significant reduction in the ratio of $p$-Akt to Akt $(P<0.05)$ and a nonsignificant downregulation of the ratio of $p-m T O R$ to $m T O R(P>0.05)$.

The western blotting quantification of autophagy marker proteins is shown in Fig. $6 \mathrm{C}$ and $6 \mathrm{D}$. Compared with the Ang1-7 group, the BEZ235 group showed increases in both the ratio of LC3-II to LC3-I and the protein expression level of p62. The increase in p62 expression was significant $(P<0.05)$ relative to the Ang1-7 group, while that in the LC3-II/I ratio was not $(P>0.05)$.

\section{Discussion}

Ang1-7 is an important bioactive peptide belonging to the renin-angiotensin system. Recent research has shown that Ang1-7 can counteract the deleterious effects of angiotensin II-induced cardiomyocyte autophagy, play a pro-survival role in human aortic endothelial cells by upregulating the autophagy process, and inhibit autophagy in the brain in spontaneously hypertensive rats ${ }^{[28-31]}$. In 2012, our group was the first to confirm the expression of the angiotensin-converting enzyme 2 (ACE2)-Ang1-7-Mas axis in the pancreas in an animal model of SAP, which suggested that Ang1-7 may be important in the pathogenesis of pancreatitis ${ }^{[22]}$. In our rat SAP model, the pathological scores of the pancreatic tissue were greatly decreased in the Ang1-7 group as compared to the SAP group, indicating that Ang1-7 exerted protective effects against pancreatic damage by attenuating the pathological changes of bleeding, inflammatory cell infiltration, acinar cell necrosis, and pancreatic edema.

LC3 is the best studied marker of autophagy. When the autophagy response is activated, LC3- $\rrbracket$ conjugates with phosphatidylethanolamine and transforms into LC3-囚, which associates with the autophagosomal membrane, segregating part of the cellular substrates that are going to degenerate into autophagosomes ${ }^{[32,33]}$. The protein p62, an autophagy cargo receptor possessing short LC3-interacting regions (LIRs) that binds with ATG8L proteins, can bridge ATG8 family members (LC3) to polyubiquitin (target-degrading proteins) ${ }^{[34-38]}$. In the late stage of the autophagy response, autophagosomes fuse with endosomes and then with lysosomes, generating autolysosomes, where the proteins LC3- $\$ and p62

are finally degraded ${ }^{[39-41]}$. Chloroquine can inhibit the fusion of autophagosomes and lysosomes, and therefore, prevent the degradation of autophagosomes; so, it is usually used to research the autophagy response and detect the exact level of autophagy flow. In our study, the protein expressions of LC3-区/ $/ \mathbb{Z}$ 
and p62 significantly increased after the induction of SAP in rats and after the treatment of AR42J cells with $\mathrm{CAE}$ and chloroquine, indicating that the autophagy response was upregulated in SAP.

The PI3K/AKT/mTOR (phosphatidylinositol 3-kinase/AKT/mammalian target of rapamycin) signaling pathway has been proved to play an important role in the autophagy process, exerting an anti-autophagy function in AP ${ }^{[42]}$. BEZ235 is a dual PI3K/mTOR inhibitor that binds to the ATP-binding pocket of these enzymes and inhibits PI3K (p110a/ $\beta / \delta / \gamma)$ and mTOR complexes ${ }^{[43,44]}$. After the administration of Ang17 , the autophagy-related protein markers significantly reduced both in vivo and in vitro, showing that Ang1-7 could alleviate the autophagy response in pancreatitis; furthermore, blocking the PI3K/Akt/mTOR pathway remarkably counteracted this effect. Therefore, our study revealed that Ang1-7 is capable of offsetting autophagy in SAP through the PI3K/Akt/mTOR pathway.

\section{Conclusions}

In this study, we first found that Ang1-7 is a potential novel drug to reverse the dysfunctional autophagy response in patients with pancreatitis. And Ang1-7 might exert its anti-autophagy function by the $\mathrm{PISK} / \mathrm{AKT} / \mathrm{mTOR}$ signaling pathway.

\section{Abbreviations}

AP

acute pancreatitis; SAP:severe acute pancreatitis; ATG5:autophagy-related gene 5; Ang1-7:angiotensin-(17); CAE:caerulein; LC3:microtubule-associated protein 1 light chain 3; p62:p62/SQSTM;

PMSF:phenylmethylsulfonyl fluoride; RIPA:radioimmunoprecipitation assay; PVDF:polyvinylidene fluoride; ECL:enhanced chemiluminescence; AMYa:a-amylase; TBST:Tris-buffer saline/Tween 20; SD:standard deviation; ACE2:angiotensin-converting enzyme 2; LIRs:LC3-interacting regions; PI3K:phosphatidylinositol 3-kinase; mTOR:mammalian target of rapamycin.

\section{Declarations}

\section{Ethics approval and consent to participate}

The experimental procedures and ethical requirements of the present study conformed to the Laboratory Animal Management Regulations of the People's Republic of China. All experimental procedures were approved by the Animal Experimental Committee of Capital Medical University (Beijing, China). Our study was carried out in compliance with the ARRIVE guidelines.

\section{Consent for publication}

Not applicable.

\section{Availability of data and materials}


The analyzed datasets generated during the study are available from the corresponding author on reasonable request.

\section{Competing interests}

The authors declare that they have no competing interests.

\section{Funding}

This work was supported by National Natural Science Foundation of China (N0.81571933).

\section{Authors' contributions}

$\mathrm{CH}$ Yin, RX Liu, and CY Li conceived and designed the experiments. CY Li, XZ Yu, WK Hu, YN Guo, XY Wang, and TY Cui performed the experimental researches, and CY Li was responsible for the main part. CY Li finished data interpretation and writing. All authors critically reviewed this report and approved the final version.

\section{Acknowledgements}

We wish to recognize the contribution of our colleagues and the expert panel members, without whom this initiative could not have come to fruition.

\section{References}

1. Anne F, Peery, Seth D, Crockett, Alfred S, Barritt, et al. Burden of gastrointestinal, liver, and pancreatitic diseases in the United States. Gastroenterology. 2015;149:1731-41e3.

2. Crockett SD, Wani S, Gardner TB, Falck-Ytter Y, Barkun A, Crockett S, et al. American gastroenterological association institute guideline on initial management of acute pancreatitis. Gastroenterology. 2018;154(4):1096-101.

3. Petrov MS, Shanbhag S, Chakraborty M, Phillips AR, Windsor JA. Organ failure and infection of pancreatic necrosis as determinants of mortality in patients with acute pancreatitis. Gastroenterology. 2010;139(3):813-20.

4. Somashekar G, Krishna, Amrit K, Kamboj, Phil A, Hart, et al. The changing epidemiology of acute pancreatitis hospitalizations: a decade of trends and the impact of chronic pancreatitis. Pancreatology. 2017;17:32-40.

5. Koutroumpakis E, Slivka A, Furlan A, Dasyam AK, Dudekula A, Greer JB, et al. Management and outcomes of acute pancreatitis patients over the last decade: a US tertiary-center experience. Pancreatology. 2017;17:32-40.

6. Salvador, Pérez, Javier, Pereda, Luis, Sabater, et al. Redox signaling in acute pancreatitis. Redox Biol. 2015;5:1-14. 
7. Waldthaler A, Schütte K, Malfertheiner P. Causes and mechanisms in acute pancreatitis. Dig Dis. 2010;28:364-72.

8. Kavitha Y, Geetha A. Anti-inflammatory and preventive activity of white mulberry root bark extract in an experimental model of pancreatitis. J Tradit Complement Med. 2018;8:497-505.

9. Hashimoto D, Ohmuraya M, Hirota M, Yamamoto A, Suyama K, Ida S, et al. Involvement of autophagy in trypsinogen activation within the pancreatic acinar cells. J Cell Biol. 2008;181:106572.

10. Sah RP, Garg P, Saluja AK. Pathogenic mechanisms of acute pancreatitis. Current Opinion in Gastroenterology. 2012;28:507-15.

11. Hashimoto D, Ohmuraya M, Hirota M, Yamamoto A, Suyama K, Ida S, et al. Involvement of autophagy in trypsinogen activation within the pancreatic acinar cells. J Cell Biol. 2008;181:106572.

12. Cao Y, Yang W, Tyler MA, Gao X, Duan C, Kim So, et al. Noggin attenuates cerulein-induced acute pancreatitis and impaired autophagy. Pancreas. 2013;42:301-7.

13. Gukovskaya AS, Gukovsky I, Algül H, Habtezion, A. Autophagy, Inflammation, and Immune Dysfunction in the Pathogenesis of Pancreatitis. Gastroenterology. 2017;153:1212-26.

14. Singh P, Garg PK. Pathophysiological mechanisms in acute pancreatitis: Current understanding. Indian J Gastroenterol. 2016;35:153-66.

15. Biczo G, Vegh ET, Shalbueva N, Mareninova OA, Elperin J, Lotshaw E, et al. Mitochondrial Dysfunction, Through Impaired Autophagy, Leads to Endoplasmic Reticulum Stress, Deregulated Lipid Metabolism, and Pancreatitis in Animal Models. Biczo G Gastroenterology. 2018;154:689-703.

16. Nussberger J, Brunner DB, Nyfeler JA, Linder L, Brunner HR. Measurement of immunoreactive angiotensin-(1-7) heptapeptide in human blood. Clinical chemistry. 2001;47:726-9.

17. Wang C, Wang Y, McNutt MA, Zhu W. Autophagy process is associated with anti-neoplastic function. Acta Biochimica et Biophysica Sinica. 2011;43:425432.

18. Rubinsztein DC, Marino G, Kroemer G. Autophagy and aging. Cell. 2011;146:682-95.

19. Levine B, Packer M, Codogno P. Development of autophagy inducers in clinical medicine. J Clin Invest. 2015;125:14-24.

20. Orlichenko L, Stolz DB, Noel P, Behari J, Liu S, Singh VP. ADP-ribosylation factor 1 protein regulates trypsinogen activation via organellar trafficking of procathepsin B protein and autophagic maturation in acute pancreatitis. J Biol Chem. 2012;287:24284-93.

21. Kroemer G. Autophagy: a druggable process that is deregulated in aging and human disease. $\mathrm{J}$ Clin Invest. 2015;125:1-4.

22. Wang Y, Wang J, Liu R, Qi HY, Wen Y, Sun FF,et al. Severe acute pancreatitis is associated with upregulation of the ACE2-angiotensin-(1-7)-Mas axis and promotes increased circulating angiotensin-(1-7). Pancreatology. 2012;12:451-7. 
23. Liu RX, Qi HY, Wang J, Wang Y, Cui LJ, Wen Y, et al. Angiotensin-converting enzyme (ACE and ACE2) imbalance correlates with the severity of cerulein-induced acute pancreatitis in mice. Exp Physiol. 2014;99:651-63.

24. Wang J, Liu RX, Qi HY, Wang Y, Cui LJ, Wen Y, et al. The ACE2-angiotensin-(1-7)-Mas axis protects against pancreatic cell damage in cell culture. Pancreas. 2015;44:266-72.

25. Wang Y, Wang G, Cui L, Liu R, Xiao H, Yin C. Angiotensin 1-7 ameliorates caerulein-induced inflammation in pancreatic acinar cells by downregulating Toll-like receptor $4 /$ nuclear factor-kB expression. Mol Med Rep. 2018;17(3):3511-8.

26. Wang X, Liu M, Hu W, Cui T, Yu X, Liu R, et al. Angiotensin-(1-7) Treatment Restores Pancreatic Microcirculation Profiles: A New Story in Acute Pancreatitis. Pancreas. 2020;49(7):960-6.

27. Schmidt J, Rattner DW, Lewandrowski K, Compton CC, Mandavilli U, Knoefel WT, et al. A better model of acute pancreatitis for evaluating therapy. Ann Surg. 1992;215:44-56.

28. Lin L, Liu XB, Xu JF, Weng LQ, Ren J, Ge JB, et al. Mas receptor mediates cardioprotection of angiotensin-(1-7) against Angiotensin II-induced cardiomyocyte autophagy and cardiac remodelling through inhibition of oxidative stress. J Cell Mol Med. 2016;20(1):48-57.

29. Wang HJ, Chen SF, and Lo WY. Identification of Cofilin-1 Induces G0/G1 Arrest and Autophagy in Angiotensin-(1-7)-treated Human Aortic Endothelial Cells from iTRAQ Quantitative Proteomics. Sci Rep. 2016;6:35372.

30. Jiang T, Gao L, Zhu XC, Yu JT, Shi JQ, Tan MS, et al. Angiotensin-(1-7) inhibits autophagy in the brain of spontaneously hypertensive rats. Pharmacol Res. 2013;71:61-8.

31. Westermeier F, Bustamante M, Pavez M, García L, Ocaranza MP, Lavandero S. Novel players in cardioprotection: Insulin like growth factor-1, angiotensin-(1-7) and angiotensin-(1-9). Pharmacol Res. 2015;101:41-55.

32. Rubinsztein DC, Gestwicki JE, Murphy LO. Potential therapeutic applications of autophagy. Nat Rev Drug Discov. 2007;6:304-12.

33. Diakopoulos KN, Lesina M, Wörmann S, Song L, Aichler M, Schild. Impaired Autophagy Induces Chronic Atrophic Pancreatitis in Mice via Sex- and Nutrition-dependent Processes. Gastroenterology. 2015;148:626-38.

34. Boyle KB, Randow F. The role of 'eat-me' signals and autophagy cargo receptors in innate immunity. Curr Opin Microbiol. 2013;16:339-48.

35. Li N, Wu XF, Ryan G. Holzer, Jun-Hee Lee, Michael Karin. Loss of acinar cell IKKa triggers spontaneous pancreatitis in mice. J Clin Invest. 2013;123:2231-43.

36. Su H, Wang X. p62 Stages an interplay between the ubiquitin-proteasome system and autophagy in the heart of defense against proteotoxic stress. Trends Cardiovasc Med. 2011;21:224-8.

37. Gao WT, Chen ZX, Wang W, Stang Michael T, Zhu WG. E1-like activating enzyme Atg7 is preferentially sequestered into p62 aggregates via its interaction with LC3-I. PLoS One. 2013;8:e73229. 
38. Jansen HJ, van Essen P, Koenen T, Joosten LAB, Netea MG, Tack CJ, et al. Autophagy activity is upregulated in adipose tissue of obese individuals and modulates proinflammatory cytokine expression. Endocrinology. 2012;153:5866-74.

39. Anna S. Gukovskaya, llya Gukovsky. Autophagy and pancreatitis. Am J Physiol Gastrointest Liver Physiol. 2012;303:993-1003.

40. Daniel J Klionsky, Kotb Abdelmohsen, Akihisa Abe, Md Joynal Abedin, Hagai Abeliovich, Abraham Acevedo Arozena, et al. Guidelines for the use and interpretation of assays for monitoring autophagy (3rd edition). Autophagy. 2016. p. 33-36.

41. Mizushima N, Levine B. Autophagy in mammalian development and differentiation. Nat Cell Biol. 2010; 12: 823-30.

42. Enrico Lupia, Luca Pigozzi, Alberto Goffi, Emilio Hirsch, Giuseppe Montrucchio. Role of phosphoinositide 3-kinase in the pathogenesis of acute pancreatitis. World J Gastroenterol. 2014; 20(41): 15190-9.

43. Wise-Draper TM, Moorthy G, Salkeni MA, Karim NA, Thomas HE, Mercer CA, et al. A Phase Ib Study of the Dual PI3K/mTOR Inhibitor Dactolisib (BEZ235) Combined with Everolimus in Patients with Advanced Solid Malignancies. Target Oncol. 2017; 12(3): 323-32.

44. Wu YY, Wu HC, Wu JE, Huang KY, Yang SC, Chen SX, et al. The dual PI3K/mTOR inhibitor BEZ235 restricts the growth of lung cancer tumors regardless of EGFR status, as a potent accompanist in combined therapeutic regimens. J Exp Clin Cancer Res. 2019; 38: 282.

\section{Figures}


A

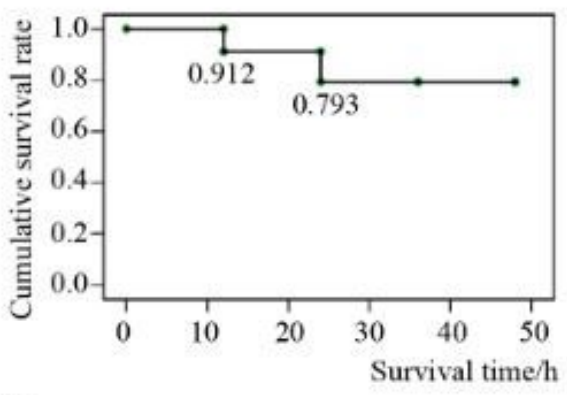

B

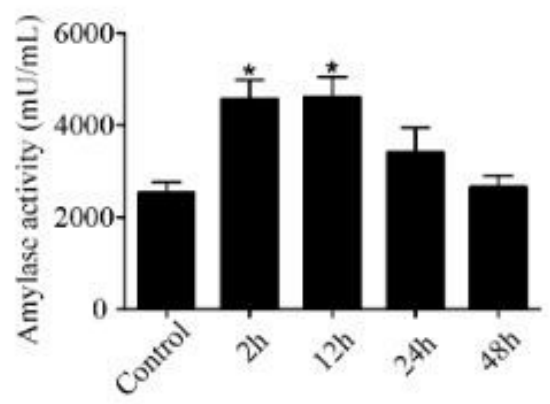

C

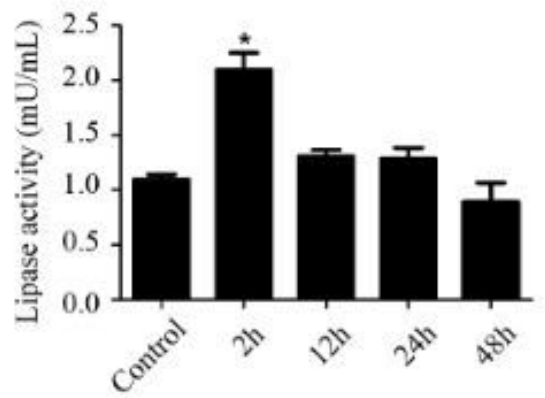

D

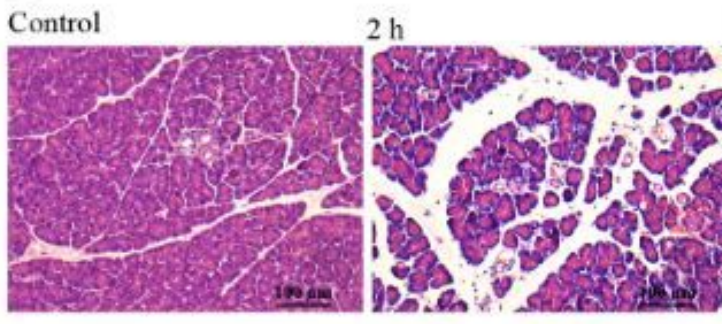

$12 \mathrm{~h} \quad 24 \mathrm{~h}$
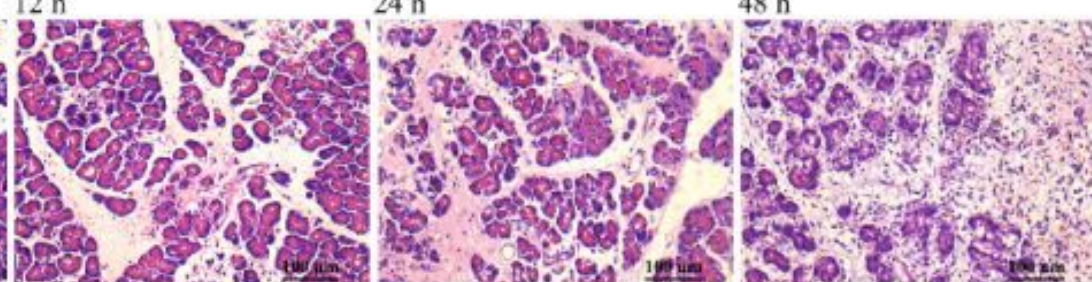

E

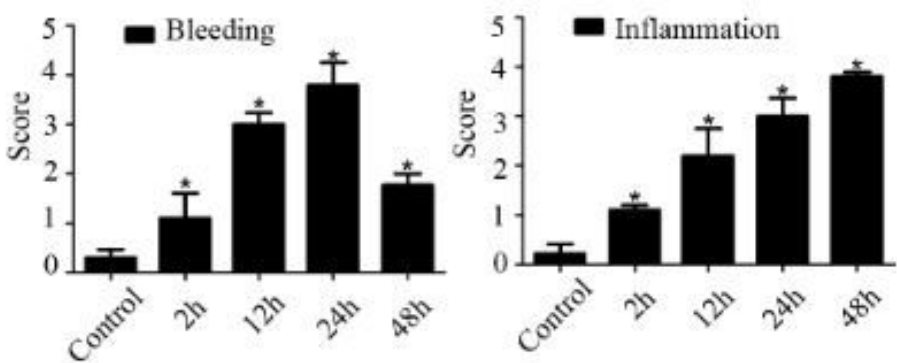

F
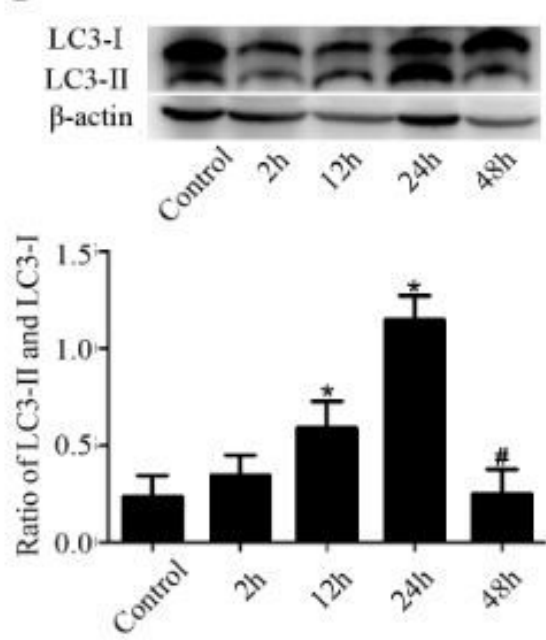
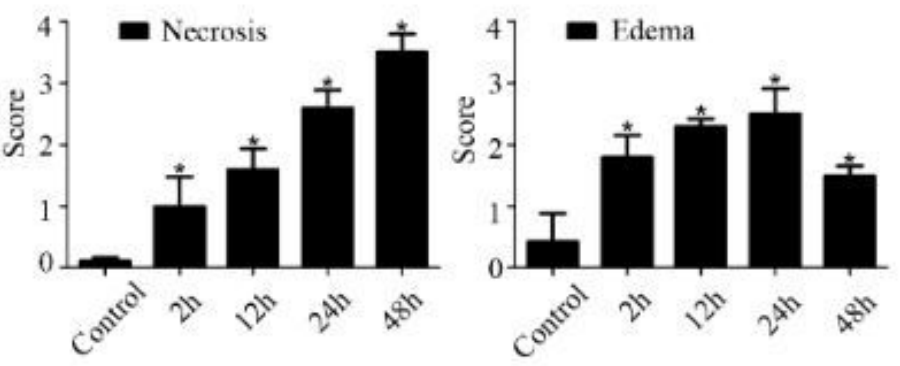

G
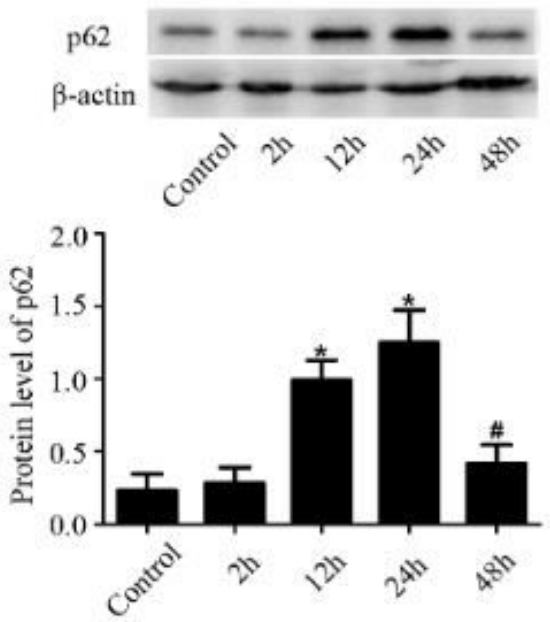

\section{Figure 1}

Autophagy markers were upregulated in the rat SAP model. (A) Kaplan-Meier survival curve of the rat severe acute pancreatitis (SAP) model showed that the total cumulative survival rate was $79.30 \%$ at $48 \mathrm{~h}$. (B and C) The serum a-amylase (AMYa) level and lipase activity. (D) Representative hematoxylin and eosin-stained pancreatic-section images obtained using an optical microscope (200x). (E) The

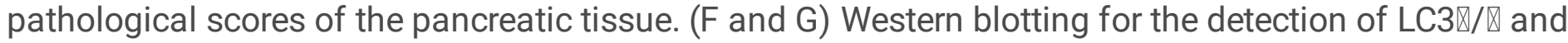


p62. The protein signals were quantified and normalized against $\beta$-actin $\left({ }^{\star} P<0.05\right.$ versus the control group, and \#P $<0.05$ versus the 24-h SAP group).
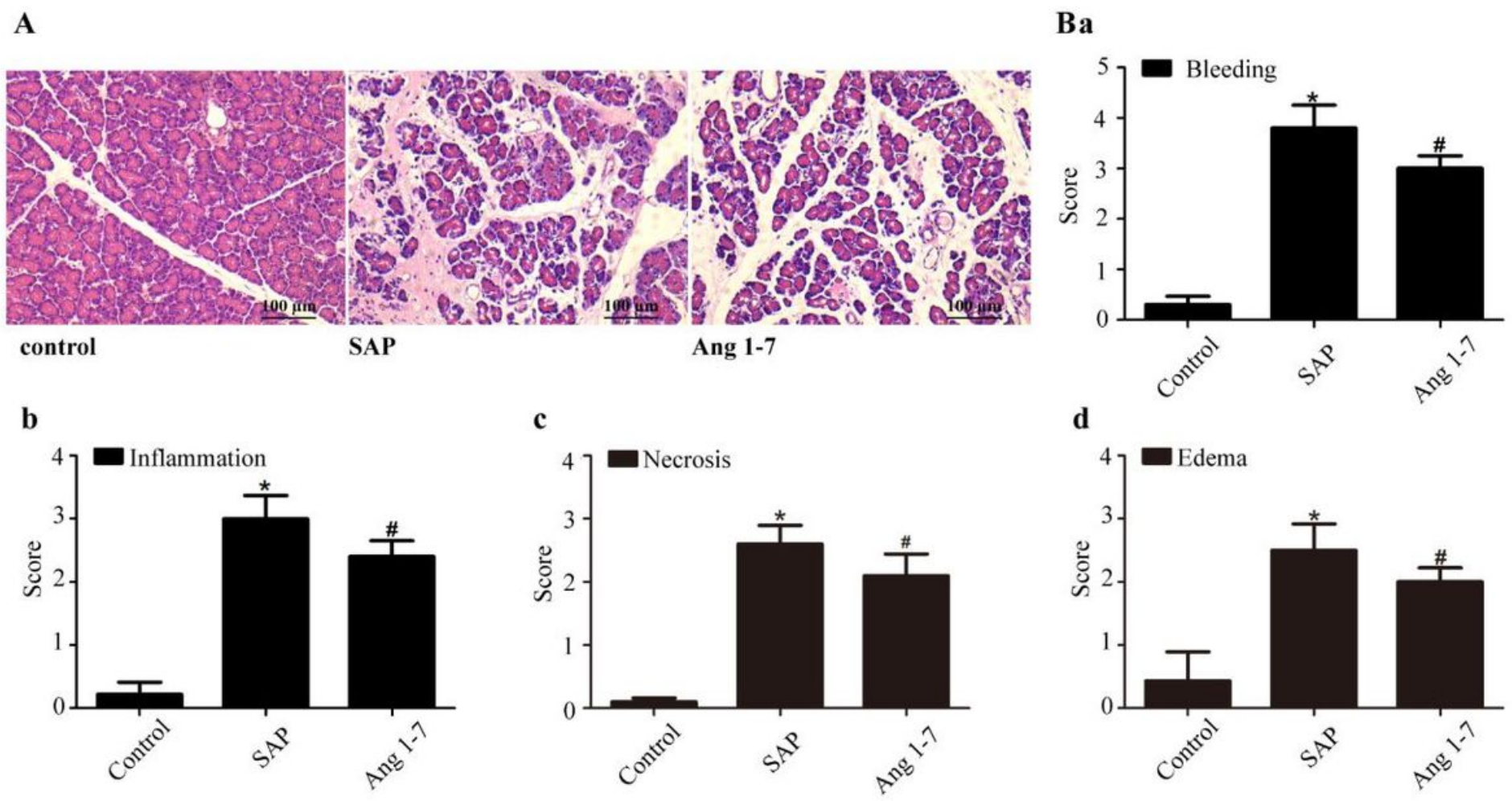

Figure 2

Ang1-7 alleviated pancreatic damage in rats with SAP. (A) Representative hematoxylin and eosin-stained pancreatic sections of control, severe acute pancreatitis (SAP), and angiotensin-(1-7) (Ang1-7) group rats (200x). (B a, b, C, and d) Pathological scores of pancreatic tissues, including the scores for bleeding, inflammation, necrosis, and edema ( ${ }^{\mathrm{P}}<0.05$ versus the control group, $\# \mathrm{P}<0.05$ versus the 24 -h SAP group). 
A Control
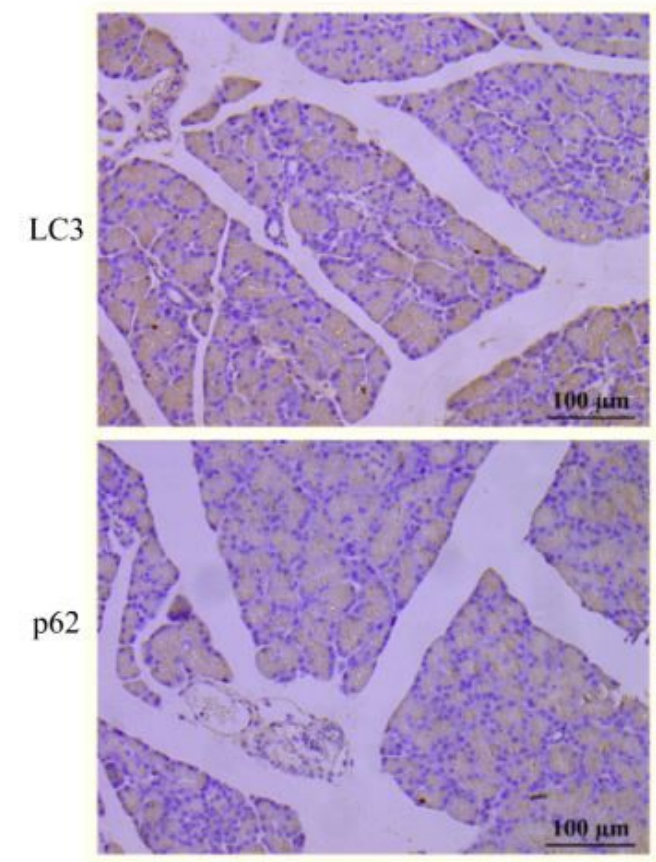

B

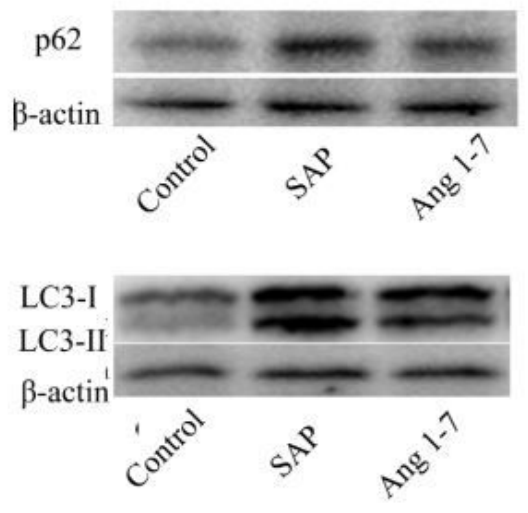

SAP
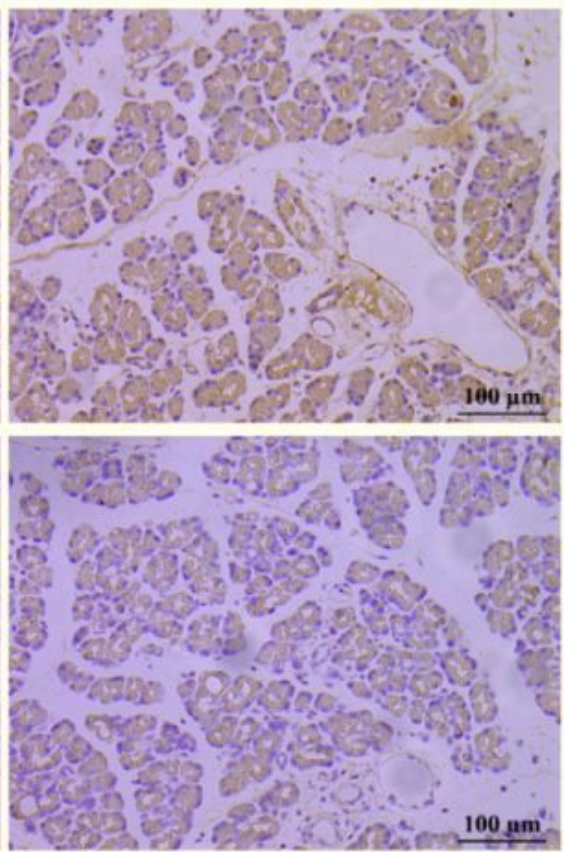

C

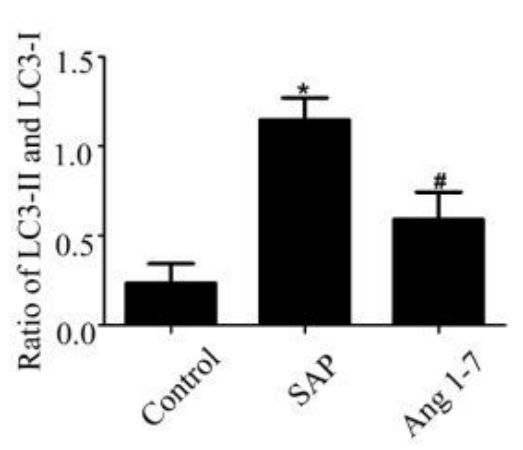

Ang 1-7
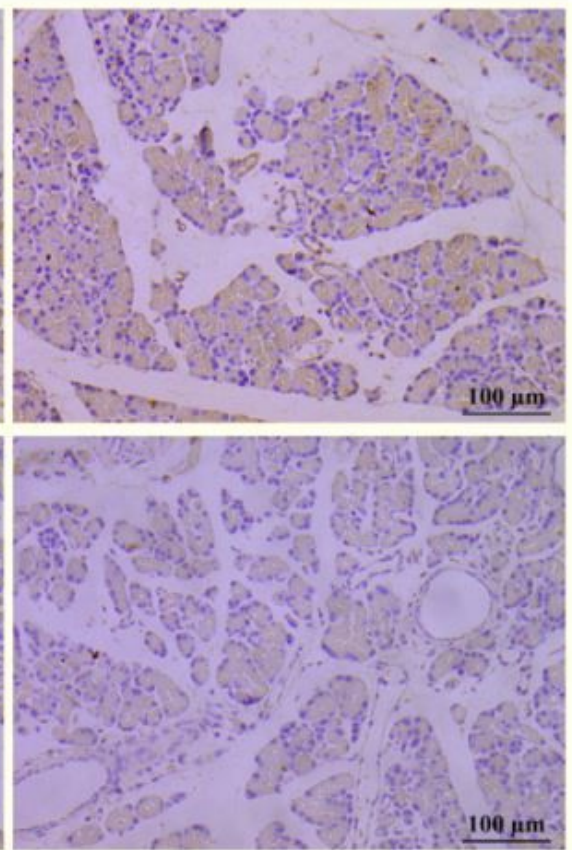

D

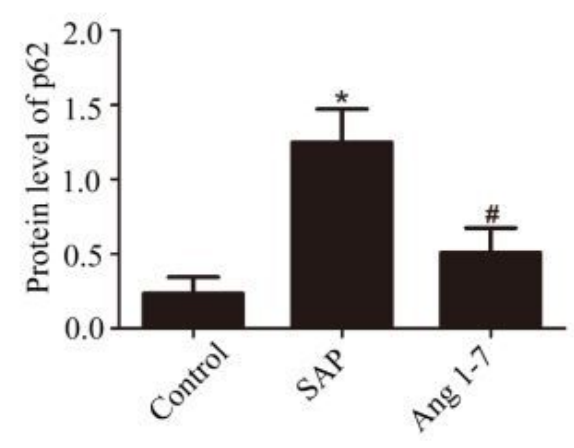

\section{Figure 3}

Ang1-7 decreased elevated autophagy-related proteins in rats with SAP. (A) Immunohistochemical analysis showing the location of the proteins LC3 and p62 in the control, severe acute pancreatitis (SAP), and angiotensin-(1-7) (Ang1-7) groups (200x). (B, C, and D) Western blotting and quantification of

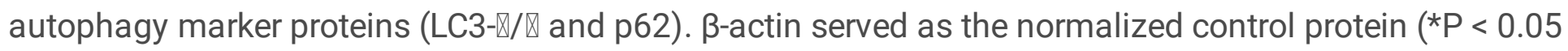
versus the control group, and \#P $<0.05$ versus the $24-\mathrm{h}$ SAP group). 
A

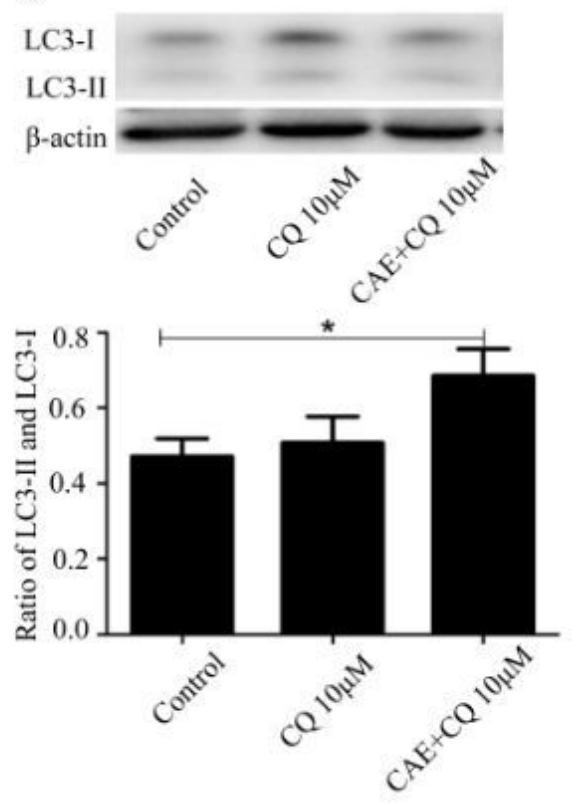

D

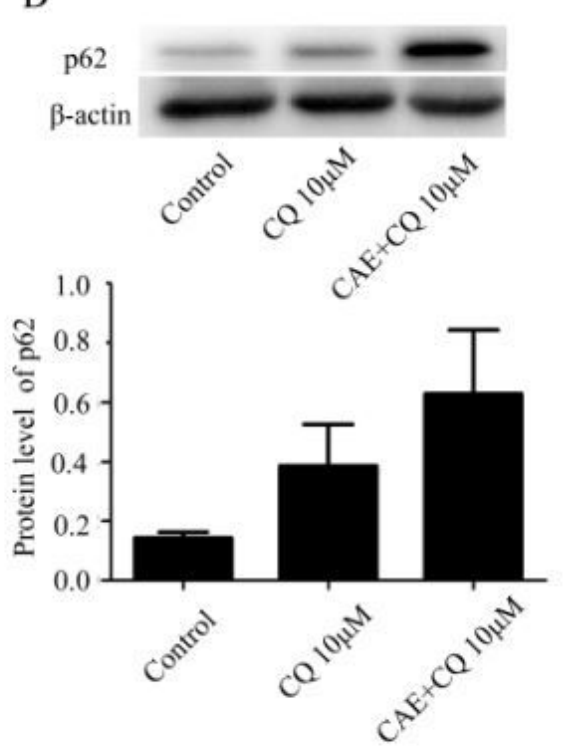

B
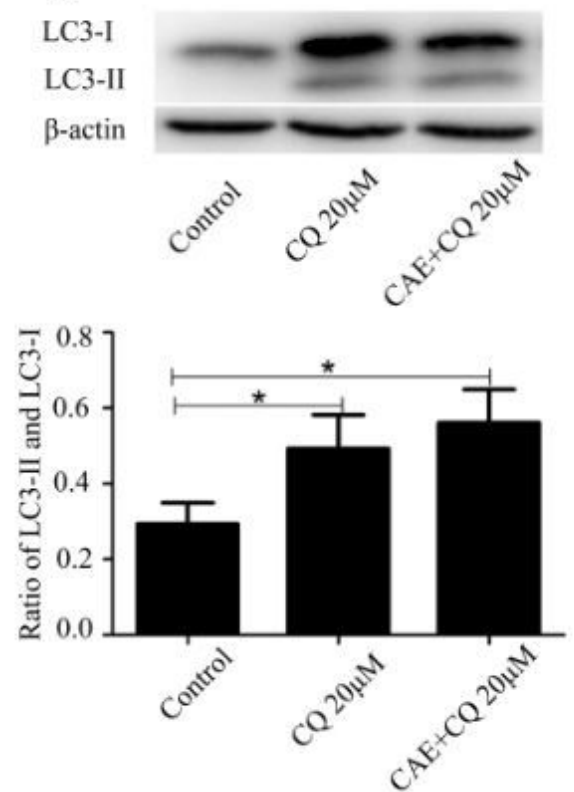

E

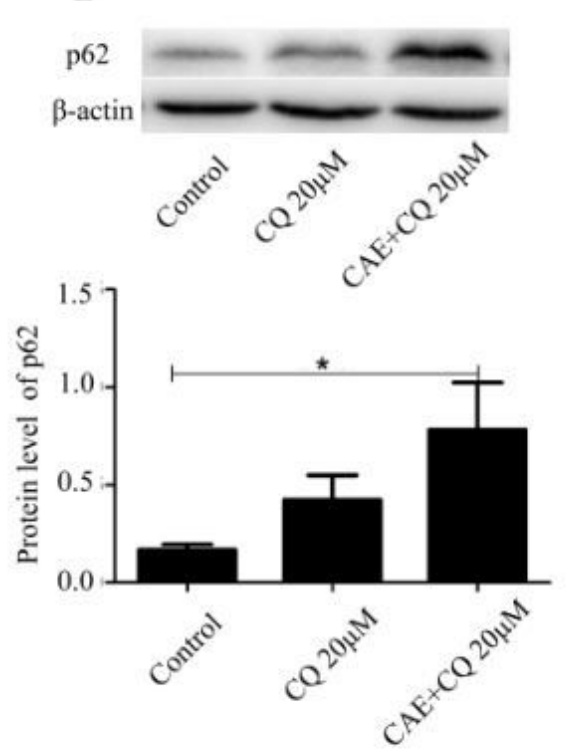

C
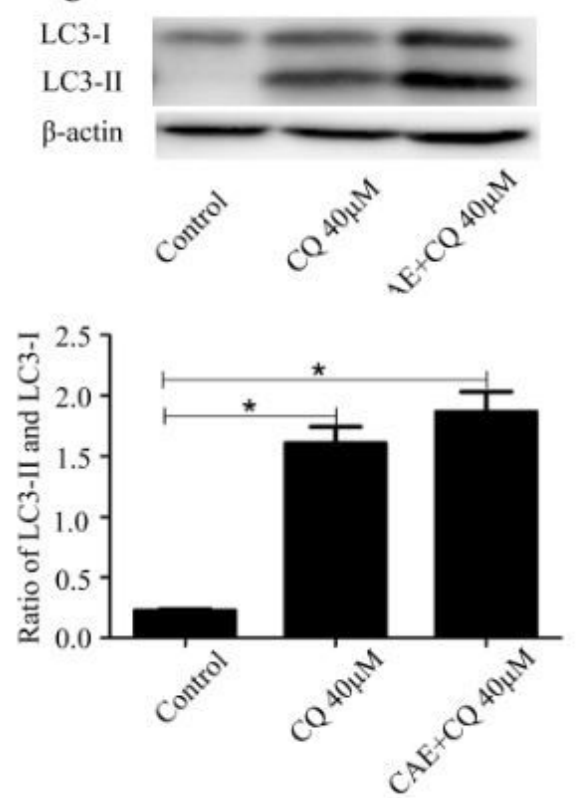

F

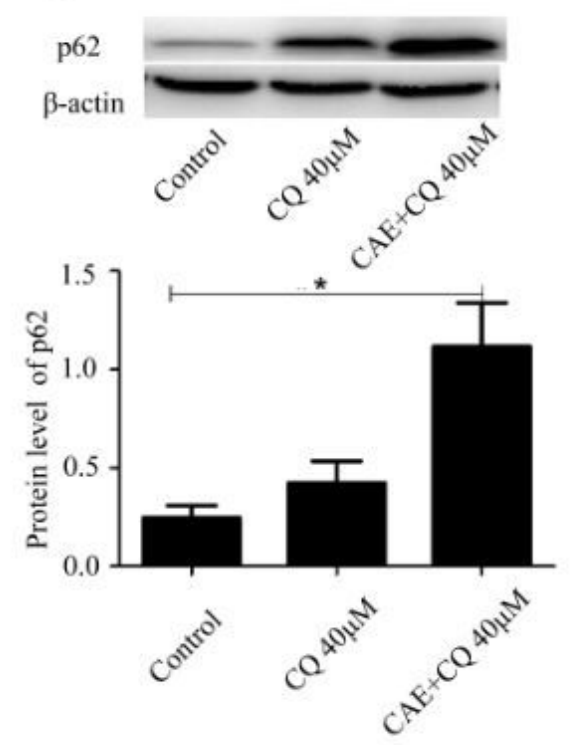

Figure 4

Chloroquine blocked autophagosome degradation in AR42J cells. Western blotting and protein quantification of the LC3- $\nabla$ to LC3- $\nabla$ ratio $(A-C)$ and the p62 level $(D-F)$ in caerulein-exposed AR42J cells treated with $10 \mu \mathrm{mol} / \mathrm{L}(A, D), 20 \mu \mathrm{mol} / \mathrm{L}(B, E)$, and $40 \mu \mathrm{mol} / \mathrm{L}(C, F)$ chloroquine $(* P<0.05)$. $\beta$-actin served as a normalized control protein. 
A
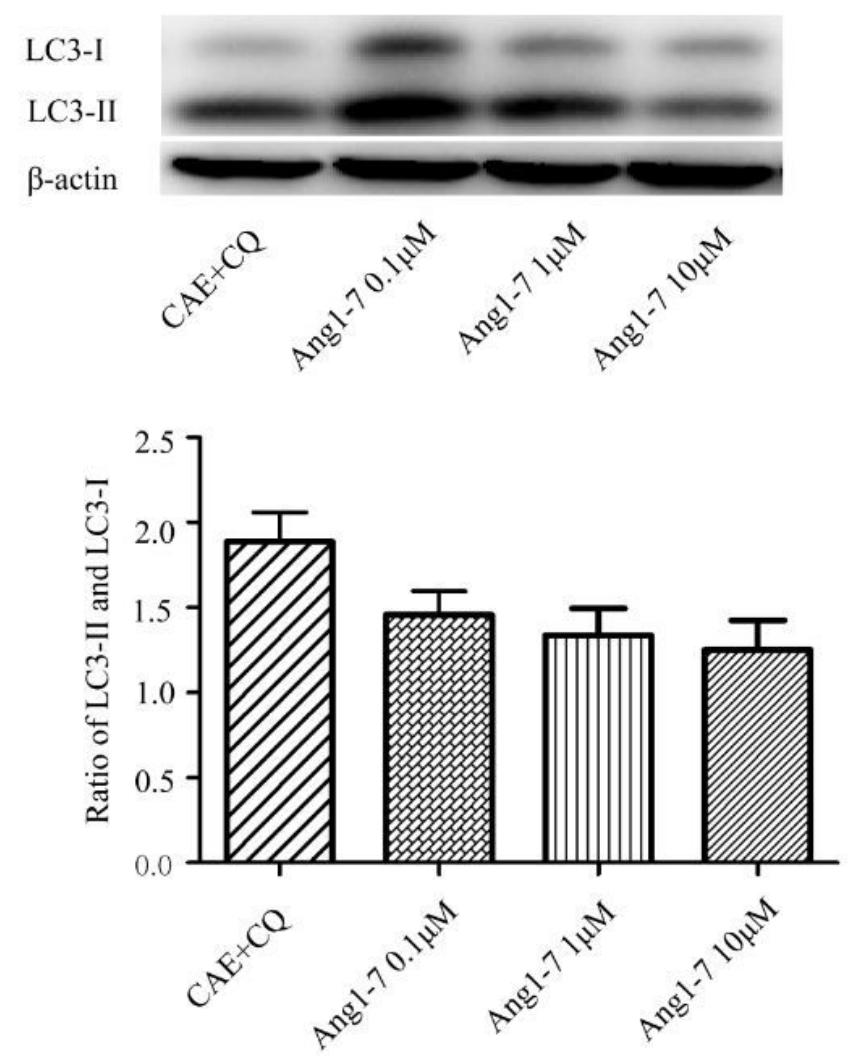

B
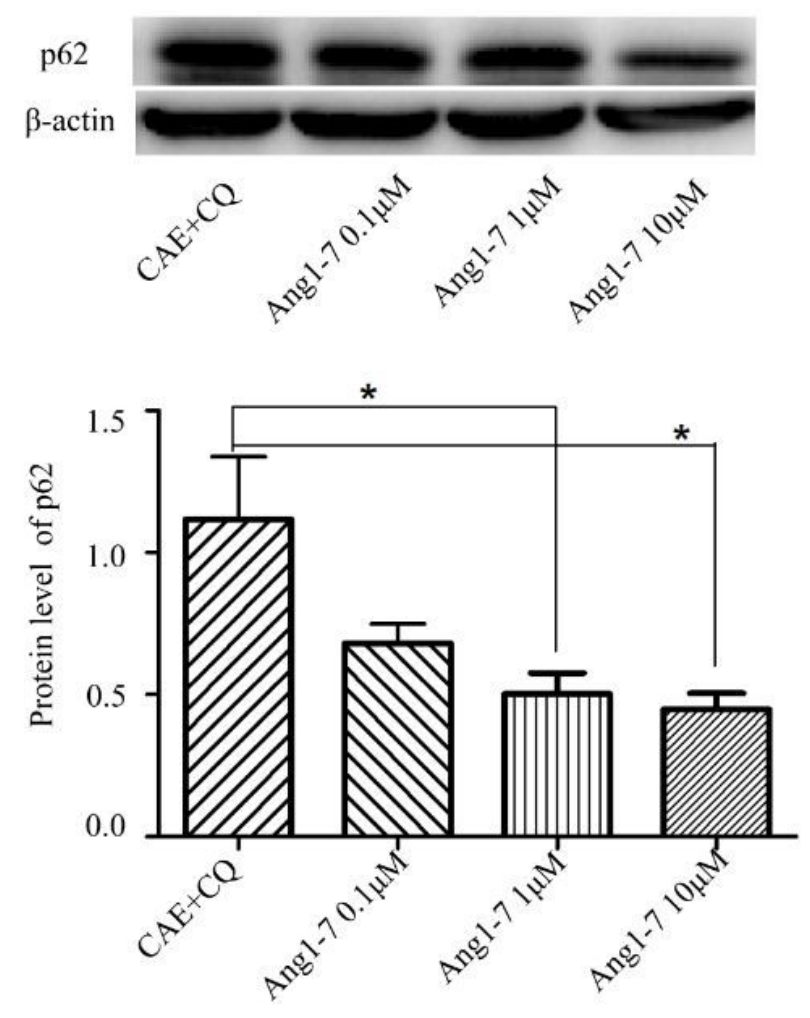

\section{Figure 5}

Ang1-7 alleviated the autophagy response in an in vitro model of CAE-induced pancreatitis. Western blotting and quantification of the autophagy marker proteins LC3-区/ $(A)$ and p62 (B) in cells treated with different concentrations of angiotensin-(1-7) (Ang1-7) $(0.1,1$, and $10 \mu \mathrm{mol} / \mathrm{L})$ as well as with caerulein $(\mathrm{CAE})$ and chloroquine (CQ). The protein signals were normalized against $\beta$-actin ( ${ }^{*} \mathrm{P}<0.05$ ). 
A

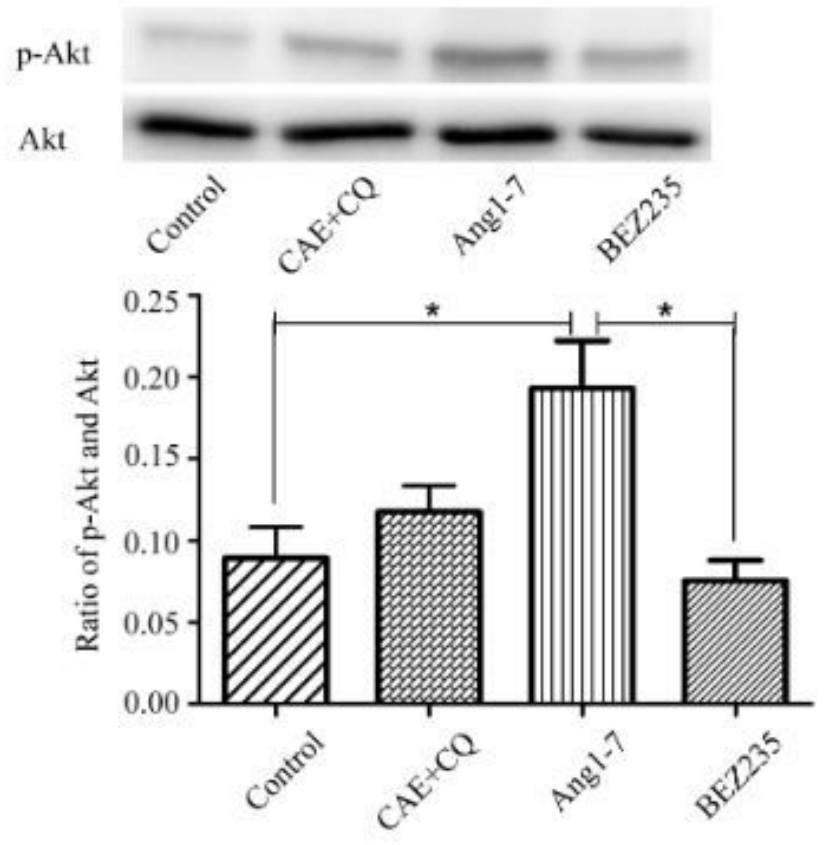

$\mathrm{C}$

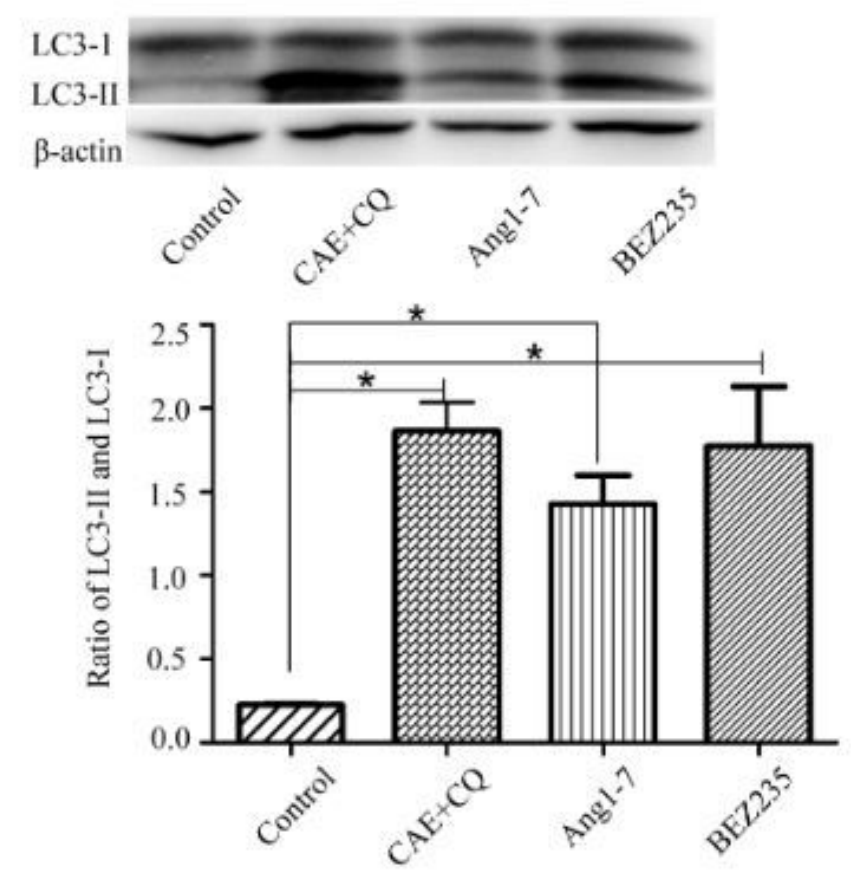

B
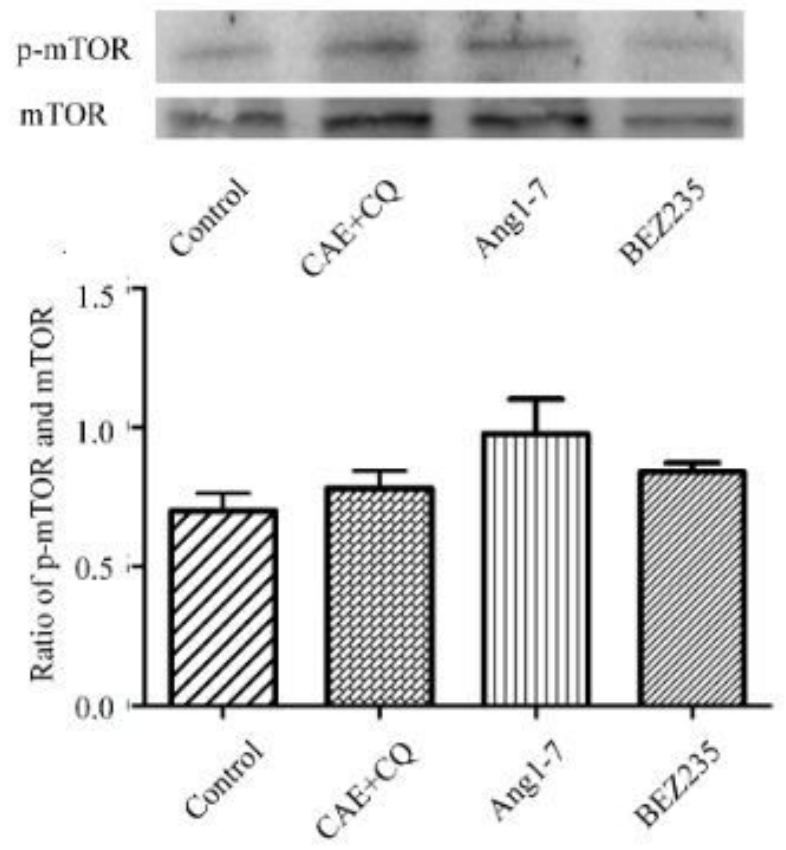

D

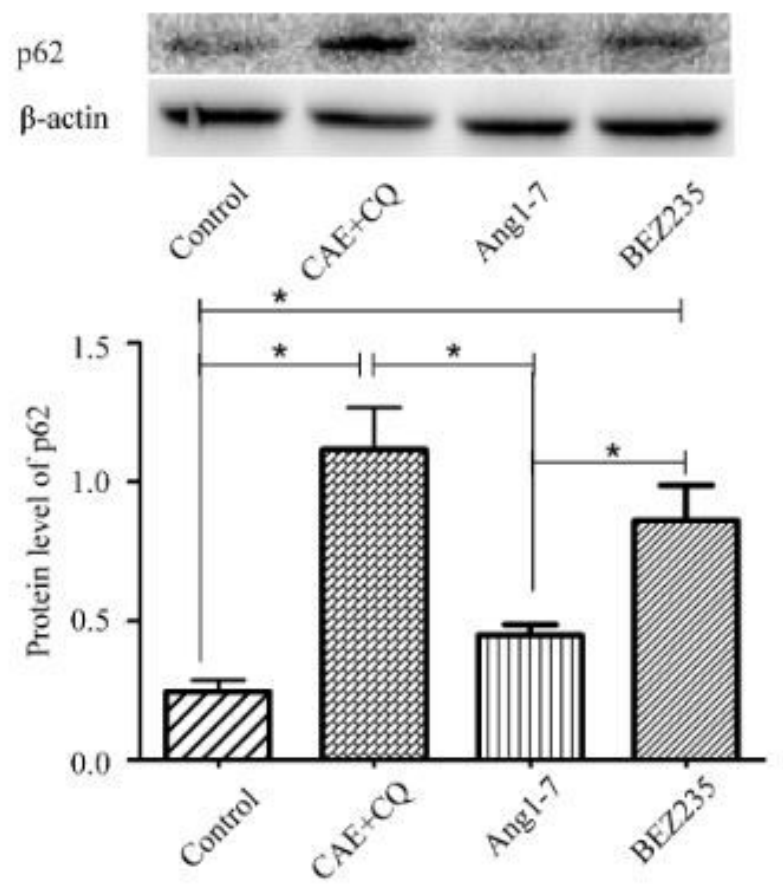

\section{Figure 6}

Autophagy response rebounded after blocking the PI3K/Akt/mTOR pathway. (A, B, C and D) Western blotting images and quantification of the ratio of p-Akt to Akt (A), the ratio of p-mTOR to mTOR (B), the

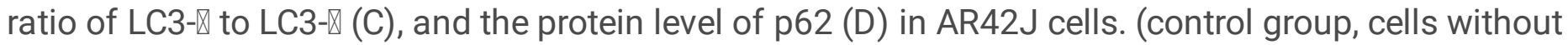
special treatment; caerulein (CAE) + chloroquine (CQ) group, cells treated with CAE and CQ; angiotensin- 
(1-7) (Ang1-7) group, cells treated with CAE, CQ, and Ang1-7; BEZ235 group, cells treated with CAE, CQ, Ang1-7, and $100 \mu \mathrm{mol} / L$ BEZ235; *P < 0.05).

\section{Supplementary Files}

This is a list of supplementary files associated with this preprint. Click to download.

- thesupplementaryfile.zip 